\title{
Os estudos sobre gênero e diversidade sexual e as proposições da pedagogia queer para constituição de contextos escolares emancipatórios
}

Gender and sexual diversity studies and the propositions of queer pedagogy for the constitution of emancipatory schooling

Anna Luiza Araújo Ramos Martins de Oliveira

Aurenéa Maria de Oliveira

Marcelo Henrique Gonçalves de Miranda

Universidade Federal de Pernambuco

\section{Resumo}

investimento discursivo em torno dos temas "diversidade sexual" e "equidade de gêneros" é indicativo de um tempo quando a certeza sobre a "naturalidade" da heterossexualidade foi desestabilizada. Este artigo revisa algumas reflexões desenvolvidas historicamente sobre o assunto e discute seus desdobramentos na educação. Enfatizam-se as contribuições dos estudos queers que analisa, a partir da lógica desconstrucionista, os mecanismos de heteronormatização da sociedade, se opõe às abordagens socioantropológicas sobre minorias sexuais e reivindica o desenvolvimento de contextos escolares emancipatórios, comprometidos com a justiça, os direitos humanos e a valorização das diferenças. $\bigcirc$ artigo chama a atenção para a heterogeneidade dos discursos, as contraditórias práticas em ação em diferentes países com tradição de pesquisa nessa área e para o estado gestacional desse debate no Brasil.

Palavras-chave: Gênero. Diversidade sexual. Estudos queers. Educação escolar.

\section{Abstract}

Discursive developments on themes like "sexual diversity" and "gender equity" are indicative of a new era where the conviction about the "naturalness" of heterosexuality was destabilized. This paper reviews some of the main reflections developed historically on this subject and discusses its implications in education. Emphasizes the contributions of queer studies, which analyzes from the deconstructionist logic, the mechanisms of heteronormativity of society, opposes the socio-anthropological approaches on sexual minorities and claim the development of emancipatory school contexts, committed to justice, human rights and valuing of differences. The paper draws attention to the heterogeneity of discourses, conflicting practices in action in different countries with tradition of research in this area, and the early stage of this debate in Brazil.

Keywords: Gender. Sexual diversity. Queerstudies. Schooling. 


\section{Introdução}

posicionamento heteronormativo, tradicionalmente assumido no contexto escolar, tem sido questionado e revisado, nos últimos anos, em decorrência da maior visibilidade das comunidades de lésbicas, gays, bissexuais e transgêneros (LGBT), do incremento da luta pelos direitos humanos e da ascendente veiculação de produtos midiáticos abordando o assunto. Percebemos um investimento discursivo em torno dos temas "diversidade sexual", "enfrentamento da homofobia", "equidade de gêneros". Disputas e novas articulações são elaboradas na esfera do Governo Federal (implantação do programa "Brasil sem Homofobia" e realização da Conferência Nacional LGBT, por exemplo), do Ministério da Educação (instituição da Secretaria de Educação Continuada, Alfabetização e Diversidade - SECAD, lançamento de editais de formação continuada nesse campo) e de algumas secretarias estaduais e municipais que vêm desenvolvendo seminários, cursos, oficinas, apresentações teatrais, visando discutir o tema com docentes e discentes da rede pública de ensino, em parceria com organizações não-governamentais. (OLIVEIRA, 2009).

No âmbito acadêmico, a produção nacional (BORRILLO, 2010; OLIVEIRA, 2009; 2011 ; OLIVEIRA; OLIVEIRA; NOVENA, 2010 ; MISKOLCI, 2007; NOVENA, 2004; LOURO, 1995; 2001 l e internacional (RASMUSSEN, 2006; RASMUSSEN; ROFES; TALBURT, 2004; FAUSTO-STERLING, 2000; MAC AN GHAIL, 1994; WEEKS, 1990) sobre gênero e diversidade sexual também é crescente. Atualmente, nos deparamos com uma área caracterizada por diversas abordagens, na qual um dos principais desafios é estabelecer, a partir dessa pluralidade, uma compreensão sobre a temática. Este artigo se propõe revisar algumas das principais reflexões sobre o assunto desenvolvidas no último século e discutir seus desdobramentos na educação. Enfatiza, especialmente, as contribuições da teoria queer, movimento teórico e político originário do diálogo entre os estudos culturais estadunidenses e o pós-estruturalismo, surgido no fim da década de 1980, como crítica às abordagens socioantropológicas sobre minorias sexuais. A perspectiva queer se propõe analisar, a partir da lógica desconstrucionista, os mecanismos de heteronormatização da sociedade e reivindica o desenvolvimento de contextos escolares emancipatórios, caracterizados pelo ensino crítico e pelo compromisso com a justiça, os direitos humanos e a valorização das diferenças. 


\section{As primeiras produções discursivas sobre gênero}

As transformações nos discursos sobre gênero ao longo da história foram marcadas, segundo Connell (2002), por vários acontecimentos e podem ser localizadas em quatro períodos: 1) de 1860 a 1920, com o advento da ciência moderna e o movimento sufragista; 2) de 1920 a 1965, com o nascimento da psicanálise, o interesse da antropologia sobre o assunto e a emergência do conceito de papéis sociais; 3) de 1965 a 1980, com a teoria do patriarcado e a revolução feminista e 4) de 1980 em diante, com a "era da diversidade" e as teorias feministas pós-estruturalistas.

período entre os anos de 1860 a 1920 é caracterizado por diversas publicações no campo científico que repercutem na noção de gênero. Os estudos de Darwin, por exemplo, introduziram a ideia de que o sexo e a escotha dos parceiros desempenham papel na evolução das espécies e que as diferenças de gênero têm base biológica. Seu pensamento teve grande influência sobre o desenvolvimento científico da época, inclusive sobre Comte (1 851 ), que propôs a função social da mulher - nutrição e cuidado dos homens - no livro "Sistema de política positiva". Após essa publicação, surgiram vários traba-

112 Hos na sociologia discutindo questões relacionadas à mulher. Entre eles, Connell (2002) destaca o livro de Jonh Mill (1 869) chamado "A subjeção da mulher" e o de Ward (1883) denominado "Sociologia dinâmica", que analisava as forças reprodutivas e criticava o modelo educacional da época por não oferecer as mesmas condições para meninas e meninos. Também ressalta a importância que tiveram as publicações "Mulher no socialismo", de August Bebel (1917) e "A origem da família, da propriedade privada e do estado", de Engels (1997), na introdução ao debate acadêmico sobre a emancipação feminina.

A conquista de territórios pelos grandes impérios econômicos e a expansão industrial também foram relevantes. Quando os navegadores chegavam a outras regiões, se deparavam com sociedades desenvolvidas em torno de diferentes formas de gênero e, mesmo considerando tais organizações primitivas, rapidamente se interessavam pelos comportamentos "exóticos" dos nativos. Suposições sobre as distinções entre homens e mulheres emergiram e, paulatinamente, iniciou-se uma reflexão sobre as estruturas sociais, as relações entre gênero e trabalho (com o conceito de parasitismo), gênero e poder (com o tema da subordinação feminina) e sexualidade (com os estudos filogenéticos). 
surgimento das teorias psicanalíticas e o desenvolvimento de conceitos como "inconsciente", "sexualidade" e "neurose" foram igualmente determinantes para esse campo. Nessa época, o movimento feminista estava em crescimento. Para Adler (1967), as causas das neuroses não estavam localizadas na sexualidade e sim na sociedade, nas relações não-igualitárias. Erikson (1971; 1976), outro psicanalista pós-freudiano, propôs uma teoria do desenvolvimento enfatizando os determinantes sociais e demonstrou que, ao longo da vida, o ser humano passa por fases específicas, marcadas por conflitos de ordem pessoal e social que interferem diretamente em sua identidade. Essas ideias foram essenciais para indagações sobre a construção social do gênero e a sua (não) determinação biológica.

Esse período também foi marcado pelo socialismo, pelo fascismo e por vários movimentos feministas. Para Connell (2002), o livro "O sexo dominante" de Mathilde Vaerting, publicado em 1921, é um marco significativo. $\bigcirc$ texto critica a noção de essência e propõe que a masculinidade e a feminilidade sejam reflexos de relações de poder. Vaerting foi uma das primeiras professoras universitárias admitida na Alemanha e demitida assim que Hitler assumiu o governo.

Os estudos antropológicos de Malinowski (1955; 1959; 1978) e de Margaret Mead (1978; 1969) estão entre os primeiros trabalhos empíricos sobre gênero e desempenharam papel expressivo no processo de relativização desse conceito. Malinowski (1978) apresentou descrições detalhadas sobre a sexualidade, o casamento e a divisão do trabalho entre os habitantes das ithas Trobriands. Margaret Mead (1978) mostrou que a adolescência é vivenciada de distintos modos e que o temperamento não é biologicamente determinado, nem depende do sexo. Ao contrário das culturas ocidentais, nas quais homens eram tidos como naturalmente agressivos e as mulheres tranquilas e caseiras, na região de Papua Nova Guiné, a autora encontrou diferentes configurações: entre os Arapesh, os homens e as mulheres apresentavam temperamento pacífico e não se envolviam em guerras; na tribo Mundugumor, tanto homens como mulheres tinham temperamento bélico; nos Tchambuli, os homens dedicavam boa parte de seu tempo para se embelezarem, enquanto as mulheres trabalhavam.

A relativização do gênero contribuiu para o surgimento e popularização da teoria dos papéis sexuais, de acordo com a qual as condutas são reflexos das normas culturais e das posições que as pessoas ocupam na sociedade. Um dos principais representantes dessa abordagem foi Parsons (1956), 
sociólogo americano, funcionalista, que definiu o papel masculino como o de líder instrumental que deve garantir o sustento e satisfação das necessidades básicas da família, e o feminino como o de líder expressivo, responsável pelo bem-estar do lar. Na análise de Connell (2002), as ideias de Parsons (1956) deslocaram as discussões sobre gênero para a questão da socialização, no entanto ainda estavam atreladas à concepção de integração e estabilidade da sociedade e tomavam como base, apenas, o modelo familiar americano. Os trabalhos de Goffman (1966; 1975) sobre papéis sociais também foram relevantes. Ao propor a metáfora da dramaturgia para analisar a variabilidade de identidades num mesmo contexto, destacou o caráter situacional dos papéis sociais e comparou a vida ao palco de um teatro.

"O segundo sexo" de Beauvoir (1986), publicado pela primeira vez em 1949, é apontado como a grande renovação na teoria sobre gênero do meio do século XX. Caracteriza-se por uma crítica política à subordinação feminina e desempenhou proeminente papel na transformação das ideias sobre a homossexualidade e a masculinidade.

Beauvoir explorou como as mulheres são constituídas como 'outro' na consciência do homem. Ela, através de uma extraordinária série de imagens sociais, investigou a variedade de possibilidades nas quais mulheres podem responder a estas situações e constituírem a si mesmas - não escapando do gênero, mas realizando gênero diferentemente nos distintos projetos de vida. (CONNELL, 2002, p. 124).

Nos anos entre 1960 e 1980, o movimento feminista expandiu-se e foi marcado por duas importantes tendências: o movimento pela igualdade de direitos entre homens e mulheres (equal rights feminism) e o movimento de libertação das mulheres (woman's liberation movement), também conhecido como feminismo radical. Segundo Bryson (2003), uma das principais representantes do movimento pela igualdade de direitos, foi Betty Friedan, que defendia a libertação das mulheres da "mística feminina" - imagem idealizada de esposa e dona de casa - e a implantação de um programa de educação que as habilitasse a trabalhar fora de casa. Argumentava a favor da licença de maternidade, de creches no local de trabalho, afirmava que as mulheres deveriam combinar planos de carreira com responsabilidades familiares e criar novas possibilidades de relacionamento com os homens, baseada na divisão de tarefas. 
feminismo radical, afirma Bryson (2003), apesar de compartilhar algumas ideias do movimento pela igualdade de direitos, distinguia-se pelos seguintes aspectos: 1) se autodefiniu como uma teoria que tinha por objetivo compreender, discutir e combater as raízes da opressão feminina; 2) afirmava que a dominação feminina era universal e sua base era o patriarcado; 3) defendia que as mulheres tinham interesses opostos aos dos homens e, por isso, deveriam unir-se em irmandade para alcançar sua libertação; 4) ressaltava que o poder masculino não se restringia à política e ao acesso ao trabalho, englobava a vida privada, a família e a sexualidade. Denunciava-se que as mulheres eram tratadas como objetos sexuais, reprodutoras, empregadas domésticas, mão de obra barata e que os homens herdavam benefícios sociais, psicológicos, econômicos e sexuais em decorrência de sua supremacia.

$\bigcirc$ conceito de patriarcado foi central nesse período. Para Millet ( 1985 ), esse poder está em todas as sociedades e é reforçado pela educação, pela religião, pelo estado. De tão presente no cotidiano, é visto como "natural" ou sequer é percebido. Tais ideias foram amplamente divulgadas na literatura (MILLET, 1985; FIRESTONE, 1979; GREER, 1979; 1984; FIGES, 1978; MORGAN, 1984), defendia-se a expressão da cultura feminina em oposição à dos homens e lutava-se pela construção de políticas que privilegiassem as mulheres. A ideia de que o gênero é construído a partir de expectativas sociais foi radicalizada e se tornou o principal mote de luta em defesa das mudanças. $\bigcirc$ conceito de patriarcado também foi incorporado pelos primeiros movimentos sociais de homossexuais. Destaca-se, entre as publicações nessa área, o livro de Altman (1972) denominado "Homossexual: opressão e liberação" e o de Hocquenghem (1978): "Desejo homossexual".

As conquistas alcançadas a partir desses movimentos foram múltiplas - direito à contracepção, leis trabalhistas, benefícios sociais, reconhecimento profissional - no entanto, com o desenvolvimento dos estudos acadêmicos sobre gênero, a noção de irmandade feminina e o paradigma do patriarcado foram questionados.

Nas teorias feministas, o paradigma do patriarcado, conceito universal de dominação masculina, tem privilegiado relações /de oposição) masculino e feminino e desigualdades dos sexos, num rígido recorte de territórios a ser revisto [...] Esta escolha teórica oculta muito da complexidade social, quando desconsidera sistemas de poder e subordinação, postos pelas reações de classe, 
etnias/raças e gerações em suas muitas interseções... ICOSTA, 2004, p. 25).

A partir dos anos de 1970, as pesquisas nessa área expandiram-se. No Brasil, segundo Meyer (2003), os estudos apareceram, inicialmente, associados aos movimentos de oposição à ditadura militar e, a partir da década de 1980, relacionados às discussões sobre a redemocratização do país. Apresentavam levantamentos estatísticos sobre as condições de vida de grupos de mulheres, denúncias sobre sexismo nas relações de trabalho e nas práticas educativas. Reflexões complexas despontaram, entre elas, as chamadas "teorias pós-feministas" - estudos sobre gênero articulados à perspectiva pós-estruturalista.

\section{Teorias feministas pós-estruturalistas e estudos queers}

De 1980 em diante, os estudos de gênero passaram por revisões e ampliaram suas reflexões. As categorias "homens" e "mulheres" como universais foram questionadas e as posições binárias de análise dessas relações

116 criticadas, desvendando-se desigualdades, inclusive, dentro desses grupos. Essas revisões aconteceram sob a influência dos estudos culturais e dos trabalhos de teóricos pós-estruturalistas - particularmente, de Foucault (2007; 1998), de Derrida (2005) e, mais recentemente, de Butler (2003).

Para Mac an Ghail e Haywood (2007), os estudos de gênero passaram de uma ênfase materialista - centralizada nas estruturas econômicas e sociais - para um enfoque linguístico - atentando para os sistemas simbólicos, as (micro) relações de poder, a construção de identidades e subjetividades. A emergência desses trabalhos foi influenciada por uma série de transformações sociais que marcaram as décadas de 1980 em diante: a separação entre prazer sexual, reprodução e casamento; o desenvolvimento das técnicas reprodutivas; o surgimento da epidemia hiv/aids; a maior visibilidade das comunidades LGBT; o crescimento do mercado voltado para produtos sexuais e as mudanças nos discursos médicos, psicológicos e jurídicos sobre a homossexualidade que, paulatinamente, foi deixando de ser considerada (pelo menos oficialmente) uma patologia. Nesse contexto, surgiram estudos engajados na desconstrução dos limites entre homo/heterossexualidade. Alguns/as 
pesquisadores/as e ativistas dos movimentos LGBT passaram a usar o termo queer como forma de autodesignação.

Queer é uma palavra usada desde o século XVI e significa "estranho", por sua semelhança sonora, é normalmente associada ao vocábulo queen (rainha) e, convencionalmente, era utilizado para se referir de forma pejorativa a homossexuais. Na última década do século XX, a expressão passou a ser empregada por uma vertente do movimento LGBT e da academia para marcar diferença e fazer oposição à heteronormatividade. Miskolci (2007) ressalta que, no campo acadêmico, a expressão foi usada, pela primeira vez, em 1990 por Teresa de Lauretis para identificar teóricos/as que, fundamentados/as nos estudos culturais e na perspectiva pós-estruturalista, desenvolviam estudos problematizando as noções de identidade, sujeito e gênero adotadas pelas teorias sociológicas sobre "minorias sexuais". Para Seidman (1995), os estudos queers, apesar de apresentarem divergências entre si, aproximam-se por usarem o método derridiano da desconstrução, por fundamentarem-se em leituras psicanalíticas, afirmarem o caráter discursivo da sexualidade e defenderem uma política educacional contra a normalização.

[...] foi essencial para o desenvolvimento da Teoria Queer, o conceito de suplementaridade criado por Derrida. Segundo ele, nossa linguagem opera em binarismos, de forma que o hegemônico só se constrói em uma oposição necessária a algo inferiorizado e subordinado. Assim, em um exemplo caro aos queer, a heterossexualidade só existe em oposição à homossexualidade, compreendida como seu negativo inferior e abjeto. Ainda que não expressa, a homossexualidade é o Outro sem o qual o hegemônico não se constitui nem tem como descrever a si próprio. (MISKOLCl, 2007, p. 03).

Provavelmente, uma das autoras mais influentes nos estudos sobre gênero, na atualidade, é Butler (2003). Em "Problemas de Gênero", ela desenvolve uma detalhada análise das teorias feministas e afirma que elas, além de apresentarem o termo "mulheres" como um significante estável, universal, separado das relações de classe, raça, etnia e geração, se apoiam numa noção fundacionista de sujeito. A ideia de que a política e a lei precisam representar as mulheres pressupõe a existência de um sujeito natural, não histórico, com identidade estável. Também critica a distinção entre gênero - como culturalmente construído - e sexo - como determinado por fatores biológicos: 
[...] o gênero não deve ser meramente concebido como uma inscrição cultural de significado num sexo previamente dado luma concepção jurídica); tem de designar também o aparato mesmo de produção mediante o qual os próprios sexos são estabelecidos. (BUTLER, 2003, p. 25).

O gênero, para a autora, é um meio discursivo pelo qual a concepção de sexo como algo da "natureza" é produzida e essa ideia é uma maneira de assegurar a estrutura binária (homem/mulher) do sexo e salvaguardar dogmas como o da heteronormatividade. Nesse sentido, sexo e gênero são produzidos através de práticas discursivas reguladoras.

[...] o gênero é uma identidade tenuemente constituída no tempo, instituído num espaço externo por meio de uma repetição estilizada de atos. $\bigcirc$ efeito do gênero se produz pela estilização do corpo e deve ser entendido, consequentemente, como a forma corriqueira pela qual os gestos, movimentos e estilos corporais de vários tipos constituem a ilusão de um eu permanente marcado pelo gênero [...] requer concebê-lo como uma temporalidade social constituída. Significativamente, se o gênero é instituído mediante atos internamente descontínuos, então a aparência de substância é precisamente isso, uma identidade construída, uma realidade performativa em que a platéia social mundana, incluindo os próprios atores, passa a acreditar, exercendo-a sob a forma de uma crença. (BUTLER, 2003, p. 200, grifos da autora).

Gênero, nessa perspectiva, é performativo: através de atos repetitivos o "eu de gênero" é estruturado. Se o gênero é criado através de performances sociais contínuas, as ideias de "sexo como algo da natureza", de "masculinidade verdadeira" e de "feminilidade essencial" também são inventadas/ construídas. Para Butler (2003, p. 194), isso fica mais evidente quando não há repetição e os atos de gênero se transformam ou se revelam diferentes. Nesses momentos, a identidade "fantasística" e sua constituição política são denunciadas e as descontinuidades do gênero aparecem. É o caso dos contextos LGBT, em que o "[...] gênero não decorre necessariamente do sexo e o desejo, ou a sexualidade em geral, não parece decorrer do gênero - nos quais, a rigor, nenhuma dessas dimensões de corporeidade significante expressa ou reflete a outra." A desconstrução do gênero elaborada por Butler tem inspirado o desenvolvimento de estudos sobre as estratégias que as sociedades usam para 
regular e materializar o sexo nos sujeitos, sobre as subversões das normas, as fissuras e brechas que ocorrem nos processos sociais.

Fazendo uma análise do contexto atual em que se encontram os estudos queers, Miskolci (2007) destaca a aproximação entre a teoria queer e os estudos pós-coloniais e aponta as intersecções entre raça, etnia, classe social e gênero.

Recentemente, as alianças esboçadas entre os Estudos Pós-coloniais e a Teoria Queer parecem renascer a partir de um nó da intersecção: aquele formado pelas categorias da sexualidade e raça. Não se trata apenas de aliança estratégica, mas de certo consenso de que as categorias são interdependentes em um mesmo processo de racialização do sexo e sexualização da raça [...] estaria na conexão raça-sexualidade, um nó que evidencia um mesmo processo normalizador que cria seres menos humanos ou até mesmo abjetos. (MISKOLCl, 2007, p. 11).

A diferença, portanto, é criada através da utilização de vários marcadores sociais que almejam a normalização. Miskolci e Pelúcio (2007), por exemplo, desenvolveram um estudo etnográfico entre travestis brasileiras e perceberam que, apesar de suas identidades desestabilizarem o binarismo de gênero, se submetem a um modelo de mulher heterossexual, branca e rica.

[...] quando Liza Lawer, Samantha Sheldon, Fernanda Galisteo escolhem seus nomes e sobrenomes, não o fazem de maneira casuística, mas a partir de um referencial no qual raça, classe, gênero se encontram e se combinam. Mulheres glamourosas, sexualizadas, ricas, brancas e loiras orientam essa escolha sintetizada nos nomes. (MISKOLCl; PELÚCIO, 2007, p. 07).

Para os autores, isso consiste num mecanismo de fuga da abjeção, de busca de dignidade através da imagem do outro que é reconhecido e valorizado pela sociedade. Os discursos hegemônicos são materializados nos corpos das travestis, por meio de uma busca incessante pelo branqueamento, pela feminilização e da fantasia de conquistar "[...] homens de verdade", que "sejam másculos, ativos, empreendedores." (MISKOLCl; PELÚCIO, 2007, p. 06).

Para Meyer (2003), as reflexões geradas pelos estudos pós-feministas pressupõem uma articulação intrínseca entre gênero e educação e ampliam a ideia de processo educativo, uma vez que enfatizam a construção 
e transformação dos sujeitos através de instâncias sociais - cinema, música, mídia, literatura, brincadeiras, além do contexto familiar e escolar - e destacam minuciosas estratégias pelas quais o gênero atua constituindo diferentes estruturas sociais.

\section{As pesquisas queers e suas implicações na educação escolar}

Há algumas décadas pesquisadores/as e ativistas de movimentos sociais ligados ao segmento feminista e LGBT denunciam que os currículos e práticas pedagógicas têm privilegiado o modelo heterossexual de identidade, família e afetividade, excluindo qualquer outro tipo de manifestação que fuja a esse padrão. Pesquisas ancoradas em perspectivas queers têm analisado os dispositivos da sexualidade presentes na educação escolar e revelado que essa instituição, historicamente, tem se constituído num terreno de heteronormalização, porém, ainda que lentamente, está se transformando num espaço de resistência, onde vozes, antes silenciadas, começam a ser ouvidas e reconhecidas. Apresentaremos, nessa seção, alguns estudos nesse campo, apontando suas contribuições.

O trabalho desenvolvido por Epstein e Johnson (1 998) é uma das principais referências nesse debate. Mostrou como a política educacional inglesa dos anos de 1990 (governo Thatcher) tentou regular a sexualidade a partir de referenciais heteronormativos e como o discurso pela tolerância e pela pluralidade funcionou como mecanismo de contenção de "fraturas potencialmente danosas". Ao refletir sobre escolarização e mídia, ressalta que as pedagogias culturais influenciam a organização das relações sociais e a constituição de subjetividades. Ademais, debate sobre a construção de identidades sexuais no contexto escolar e descreve como a escola, através de dinâmicas específicas, controla e disciplina a sexualidade, a maneira de falar e de se vestir de estudantes e de docentes:

Eles e elas também vestem uma espécie de uniforme. Os poucos homens trajam calças cinza de flanela e camisas de cores lisas com uma gravata e uma jaqueta (mas não um paletó). As mulheres se vestem de cores variadas, mas de estilos semelhantes. Estão vestidas de modo a parecerem 'respeitáveis'. [...] Não há nenhuma 
'última moda', nenhum indicativo de estilo heterossexual, gay ou lésbico entre os professores e as professoras. (EPSTEIN; JOHNSON, 1998, p. 111.

A partir da análise de histórias de vida de docentes homossexuais, Epstein e Johnson (1998) mostram que o discurso heterossexista das escolas é uma prática desumanizante, que tenta normalizar as sexualidades e neutralizar o corpo. Para Hooks (200 1), a formação docente centrada no dualismo corpo/mente é um dos principais determinantes da negação do corpo e do eros em sala de aula. Segundo a autora, os/as docentes são treinados/as a se centrar na racionalidade, como se o ensino fosse um processo neutro e não houvesse lugar para paixão, criatividade, diversidade na escola.

No contexto brasileiro, o trabalho de Louro (1 995) realizou um estudo sobre a construção da masculinidade numa escola confessional cristã e verificou, através da análise de narrativas de alunos, que uma das principais recomendações que a instituição fazia era a do autocontrole emocional como contar até dez e pensar antes de falar - para evitar ser dominado pelos sentimentos. $\bigcirc$ incentivo à prática de esportes competitivos por meninos é apontado como recurso para diminuir as relações de amizade e trocas de confidencialidade - atributos femininos - e para cultivar a expressão da dureza, o adestramento das emoções. Como observa a autora:

[...] passar ou não pela escola, muito ou pouco tempo, é uma das distinções sociais. Os corpos dos indivíduos devem, pois, apresentar marcas visíveis desse processo; marcas que, ao serem valorizadas por essas sociedades, tornam-se referência para todos. Um corpo escolarizado é capaz de ficar sentado por muitas horas e tem, provavelmente, a habilidade para expressar gestos ou comportamentos indicativos de interesse e de atenção, mesmo que falsos. Um corpo disciplinado pela escola é treinado no silêncio e num determinado modelo de fala; concebe e usa o tempo e o espaço de uma forma particular [...] as tecnologias utilizadas pela escola alcançam, aqui, o resultado pretendido: o auto-disciplinamento, o investimento continuado e autônomo do sujeito sobre si mesmo. (LOURO, 2001, p. 21-22).

Fundamentado em estudo etnográfico, numa escola inglesa de ensino médio, Mac an Ghaill (1994) também discorre sobre as relações entre escolarização e masculinidades e assinala a contingência dos discursos sobre gênero 
e sexualidade, desvelando a influência de fatores políticos, históricos, econômicos e ambientais - sala de aula, encontro de pais, sala dos professores - sobre os mesmos. A escola pesquisada havia passado por reestruturações em decorrência de reformas educacionais - alterações curriculares, criação de novos cursos, implementação de sistemas de avaliação e monitoramento da qualidade da educação. Tais mudanças promoveram modificações na estrutura de trabalho dos/as professores/as, em suas atuações e nas crenças sobre seus papéis. Conhecer essas crenças e os diferentes perfis foi essencial para a compreensão das relações de gênero desenvolvidas na escola. $\bigcirc$ autor identificou três perfis:

- Profissionais (25\% dos/as entrevistados/as): professores conservadores, que defendiam o retorno a uma estrutura hierárquica de administração e organização curricular; se opunham às teorias progressivas e aos movimentos antissexistas; percebiam as diferenças de gênero a partir do binarismo homem/mulher; defendiam o desenvolvimento da educação sexual centrada em aspectos biológicos e mantinham relações assimétricas com os alunos, marcadas pelo autoritarismo.

- Antigos Coletivistas (25\% dos/as entrevistados/as): faziam oposição à reforma educacional; criticavam a criação de funções de monitoramento e fiscalização do ensino, defendiam a implementação de uma pedagogia centrada no aluno e a assistência pastoral aos mesmos; eram cooperativos entre si e; defendiam as iniciativas antissexistas, antirracistas e multiculturais; desenvolviam relações próximas com os/as discentes.

- Novos empresários (50\% dos/as entrevistados/as): enfatizavam o status profissional; partiam de uma visão de gerenciamento das responsabilidades; eram a favor da implementação de um sistema de avaliação docente; adotavam diferentes práticas pedagógicas, tanto conservadoras, como progressistas (pedagogia pragmática); eram a favor da adoção de estratégias de marketing; partilhavam a concepção de educação como mercadoria e de estudantes como clientes; usavam uma linguagem "politicamente correta"; enfatizavam a igualdade de oportunidades para estudantes negros/as e do sexo feminino; apoiavam as inovações curriculares, principalmente a criação de cursos profissionalizantes. 
Segundo Mac an Ghaill (1994), os/as docentes conservadores ("profissionais"), ao falarem sobre suas identidades, remetiam-se à época em que eram alunos, à profissão de seus pais, à divisão sexual do trabalho na família, a suas experiências no exército, à prática de esportes competitivos, enfatizavam a nacionalidade inglesa e expressavam forte admiração por Thatcher. Tais elementos mnemônicos surgem como recursos para demarcar o "lugar do masculino na sociedade". Os "antigos coletivistas" remeteram-se à época em que constituíam um grupo dominante na escola. Aparentavam vivenciar uma "crise de masculinidade", um deslocamento, em decorrência da emergência dos "novos empresários". Percebiam-se com menos status e responsabilidade. Suas representações de masculinidades estavam ligadas à ideia de coletividade e ancoradas em referenciais políticos socialistas. Criticavam a opressão e defendiam a igualdade de oportunidades, porém não tinham consciência do papel desempenhado por eles no regime de gênero compartilhado na escola, dos privilégios que gozavam por serem homens, brancos e de classe média. Os "novos empresários" enfatizavam a vocação, a gestão, o instrumentalismo e o individualismo. Se autorrepresentavam como os professores ideais.

Para o autor, os dados sugerem que a construção de masculinidades no contexto escolar não acontece por meio da imposição de um padrão, mas através de um complexo jogo de lutas (que envolve contradições e fissuras), de negociações de significados e de construção de alianças estratégicas. Ao analisar as entrevistas realizadas com estudantes, observou que a escola tomava a heterossexualidade como norma e desenvolvia uma série de dispositivos para a regulação social. Um aspecto que chamou atenção foi quando o pesquisador solicitou autorização para entrevistar alunos e foi informado de que não havia gays na instituição e que discutir homossexualidade não era apropriado para estudantes. Durante as entrevistas, entretanto, vários discentes revelaram que eram gays e solicitaram total sigilo sobre suas identidades, afirmando que as escolas não os aceitariam. Os poucos materiais escolares que faziam referência à sexualidade, tratavam o tema relacionando-o apenas à heterossexualidade, à procriação e à distinção entre papéis masculinos e femininos. Os professores afirmaram que não era relevante incluir a discussão sobre homossexualidade no currículo escolar; apresentaram concepções essencialistas sobre o assunto, dizendo, inclusive, que as pessoas já nascem homossexuais; e usaram descrições do tipo: garotos afeminados, machos dominados pela mãe, práticas sexuais predatórias, doença psicológica e comportamentos doentios, 
para se referirem a adolescentes gays. A maioria percebia a homossexualidade como um comportamento "desviante" e nenhum se sentia preparado para aconselhar um aluno gay ou uma aluna lésbica. Segundo o autor:

Os estudantes crescem numa sociedade onde não há imagens positivas de pessoas gays e lésbicas. Não há conhecimento da história das conquistas de gays e lésbicas [...] quando textos escritos por gays e lésbicas foram lidos na sala de aula, nenhuma referência foi feita à orientação sexual dos autores. De fato, raramente a homossexualidade foi discutida nas lições e, nas poucas ocasiões quando ela foi introduzida, ela foi apresentada num contexto negativo, mais recentemente em relação a AIDS [...] Desta perspectiva, a heterossexualidade foi apresentada como natural, normal e universal simplesmente porque não há formas alternativas de existência. (MAC AN GHAILL, 1994, p. 161).

O silêncio sobre a diversidade sexual provoca naqueles/as que sentem desejos diferentes da norma heterossexual o isolamento, a confusão e a marginalização. A heteronormatividade, como destaca Louro (2001), vem sempre acompanhada pela rejeição declarada à homossexualidade e, na maioria das

124 vezes, pelo consentimento e incentivo a práticas escolares homofóbicas - piadinhas, desprezo, constrangimentos. Quando um aluno/a ou professor/a expressa uma atitude diferente da norma estabelecida, se torna alvo de maior vigilância, de perseguição ou, como salientam Epstein e Johnson (1 998), se transforma num mito, sendo alvo da projeção da sexualidade reprimida na escola.

A despeito de toda a hostilidade verificada no ambiente escolar, Mac an Ghaill (1994) destaca experiências positivas vivenciadas por alunos gays. Alguns estudantes disseram que "estar fora da norma" favorece o desenvolvimento do senso crítico, permite que eles não compartilhem determinados comportamentos nocivos incentivados entre os meninos - agressividade, competição, não expressão de afetividade - e favorece o desenvolvimento de relações de amizade com as meninas, porque eles não se sentem "obrigados" a tratá-las como objeto de prazer.

Britzman (2001), numa reflexão sobre currículo e sexualidade, ressalta que a estrutura escolar tem impedido uma abordagem ética e cuidadosa da sexualidade na educação. 
A cultura da escola faz com que respostas estáveis sejam esperadas e que o ensino de fatos seja mais importante do que a compreensão de questões íntimas. Além disso, nessa cultura, modos autoritários de interação social impedem a possibilidade de novas questões e não estimulam o desenvolvimento de uma curiosidade que possa levar professores e estudantes a direções que poderiam se mostrar surpreendentes. Tudo isso faz com que as questões da sexualidade sejam relegadas ao espaço das respostas certas ou erradas. (BRITZMAN, 2001, p. 85-86).

A autora afirma que a educação tem funcionado como superego, tentando instalar a culpa todas as vezes que se pensa a sexualidade como forma de prazer. Na escola, diz ela, a sexualidade está sempre atrelada a discursos de pânico moral, de eugenismo e de higiene social. Como alternativa, propõe que sejam desenvolvidos currículos e práticas pedagógicas que concebam a sexualidade em movimento, como algo que se opõe às fronteiras, que não segue as regras da cultura. Tais currículos se caracterizariam

Por sua recusa a categorias ordenadas, pelos debates que eles permitem, pelas práticas que os tornam possíveis e impossíveis e é precisamente essa dinâmica que a educação nega. Nós podemos ainda pensar na literatura, na poesia, no cinema, na música, nos murais de rua, nas peças de teatro e nos prazeres obtidos quando nos apaixonamos por pessoas e por idéias, pois nessas perspectivas imaginárias existe uma tolerância pelos desvios da vida, um interesse em estudar os inesperados movimentos de Eros e de Thanatos. Na literatura, no cinema, na arte, na música, a preocupação não está em como estabilizar o conhecimento, mas em como explorar suas fissuras, suas insuficiências, suas traições e mesmo suas necessárias ilusões. Nessas formas de arte, a incerteza pode causar ansiedade e medo, mas esses afetos podem ser explorados em todo o seu drama, sem sugerir a incompetência da leitora ou do leitor. (BRITZMAN, 2001, p. 108).

Esse tipo de projeto exige profissionais críticos, interessados em despertar a atenção dos/as alunos/as e promover relações mais igualitárias no ambiente escolar. Além disso, demanda educadores/as que tenham coragem de se posicionar politicamente e consciência de que a sexualidade está relacionada com direitos civis. 
Britzman (1996) aponta, também, para necessidade de se proporcionar conhecimento sobre a sexualidade gay e lésbica durante a formação de professores/as e enfatiza que é preciso combater alguns mitos relacionados à homossexualidade, entre eles: 1) de que ao falar em homossexualidade estamos corrompendo os jovens; 2) de que os/as estudantes são muito novos para pensar sobre identidades LGBT; e 3) de que a sexualidade faz parte apenas do domínio privado.

Outros estudos recentes destacam que diferentes discursos sobre a homossexualidade emergem no contexto contemporâneo, desestabilizando as certezas sobre a "naturalidade" da heterossexualidade e promovendo revisões nos discursos médicos, educacionais, psicológicos e jurídicos. Essa desestabilização, como ressalta Louro (2003), é profundamente perturbadora para o campo educacional, exige a construção de novas referências e a consciência de que todos/as usamos códigos para nos apresentar.

Novena (2004), num estudo sobre a produção e circulação das representações sociais da sexualidade na organização escolar, identificou diferentes e contraditórias representações da homossexualidade entre adolescentes de escolas públicas da cidade do Recife. Embora algumas explicações 126 apontassem para a homossexualidade como um fenômeno normal ou um comportamento da sociedade atual, de forma geral, essas representações apareciam vinculadas à tentativa de explicação das causas da homossexualidade (problemas familiares, doença) e à ideia de sexualidade desviante.

Gama (2004) buscou compreender como professoras do ensino fundamental em Recife, com formação em pedagogia, apreendem as discussões atuais sobre gênero e educação e articulam esse debate à vivência do currículo na escola. A partir de observações em sala de aula e entrevistas com professoras recém-formadas, a pesquisadora verificou algumas lacunas referentes à abordagem do gênero em sala de aula, como: a demarcação de espaços femininos e masculinos; a naturalização de preconceitos; expectativas diferenciadas em relação aos garotos e às garotas e dificuldades das professoras em identificar e em intervir nos conflitos entre gêneros. Oliveira (200 1), num estudo com docentes do ensino fundamental de João Pessoa, percebeu que suas representações sociais de sexualidade são organizadas em torno de conteúdos afetivos e informativos e que, embora os/as mesmos/as reconheçam a importância do tema, preconceitos, valores e normas morais norteiam suas ações e os/as deixam pouco à vontade para abordar o assunto na escola. 
Tavares (2006) realizou uma pesquisa sobre a visão de formandos/ as de licenciatura em Recife a respeito da homofobia e verificou a presença de um discurso pela tolerância quando a homossexualidade era pensada nas relações da esfera pública - entre colegas, entre alunos/as. No entanto, quando a homossexualidade se aproximava do campo privado e, de alguma forma, ameaçava a representação tradicional de família - heterossexual e nuclear - a tolerância se transformava em rejeição e ações heteronormativas emergiam. A autora também percebeu que a maioria dos/as formandos/as não tinha preparo teórico sobre o tema, muitos, inclusive, não sabiam o significado da palavra homofobia. Um aspecto interessante na pesquisa foi que estava prevista a realização de grupos focais e, apenas, duas estudantes compareceram, o que indica, entre outras coisas, a resistência em abordar o tema. A autora sugere o rompimento do silêncio em relação ao tema "homossexualidade" nos cursos de formação de professores/as e a sua substituição pela crítica ao padrão estabelecido como natural.

Resultados parciais de pesquisas (MIRANDA; OLIVEIRA, 2012) indicam a persistência da cultura heteronormativa nos discursos tanto de lideranças de movimentos sociais como de representantes de secretarias estaduais de Pernambuco e municipais de Recife e Olinda. Percebe-se que há um esforço por parte do Estado e da sociedade civil organizada que visa ao enfrentamento do preconceito e à inclusão social de grupos LGBT, mas seus profissionais ainda concebem o sexo como um fenômeno natural, dando ao mesmo o status de anterioridade em relação ao social. Observa-se, ainda, a dificuldade dos referidos setores em lidar com questões envolvendo transgêneros e travestis. Nesse sentido, por mais que ocorram debates problematizando a heteronormatividade e que o tema ganhe dimensão transversal, adquirindo visibilidade em setores estratégicos - como, por exemplo, no campo educacional - a heterossexualidade segue como modelo hegemônico e não se conseguiu ainda alcançar eficácia no combate ao estigma contra corpos modificados, entendidos socialmente por vários grupos como abjetos.

Oliveira (2009) desenvolveu um estudo sobre as dinâmicas e condições de produção do discurso pedagógico oficial pela diversidade sexual na Secretaria de Educação Continuada, Alfabetização e Diversidade (SECAD/ MEC) e no contexto das secretarias de educação em Pernambuco e percebeu que não há um discurso unificado sendo veiculado pelos órgãos oficiais de educação. Há, porém, um discurso hegemônico, construído a partir de uma 
cadeia de equivalência entre diferentes posicionamentos em torno do ponto nodal "diversidade sexual na escola". Observou, também, que, dentro dessa cadeia de equivalência, há quatro lógicas sociais principais que articulam os discursos pela diversidade sexual: a da educação inclusiva, a dos direitos humanos, a do reconhecimento das diferenças/identidades e a da orientação sexual na escola. As lógicas sociais, nessa perspectiva, são padrões de significação socialmente compartilhados a partir dos quais as práticas de atores individuais e coletivos são desenvolvidas e compreendidas. (GLYNOS; HOWARTH, 2007).

A lógica da educação inclusiva propõe o acesso universal à educação como meio de eliminação das desigualdades sociais - étnico-raciais, geracionais, de classe social, de gênero etc. A dos direitos humanos defende os direitos de LGBT, sobretudo o acesso à educação e o direito à livre orientação afetivo-sexual, sendo o combate à homofobia no ambiente escolar o eixo central do discurso. A lógica do reconhecimento das diferenças/identidades busca, de forma mais geral, a desconstrução das posturas essencialistas em relação à normalidade - de gênero, étnico-racial, de orientação sexual - e das estruturas de hierarquia e subordinação social a elas inerente. Para isso, 128 lança mão da linguagem da crítica científica através da articulação entre diversas disciplinas e entre academia e movimentos sociais. A lógica da orientação sexual sustenta que sejam desenvolvidas atividades na escola para discussão de questões relacionadas à sexualidade, envolvendo os temas: corpo humano, relações de gênero e prevenção a doenças sexualmente transmissíveis (DST) e à Síndrome da imunodeficiência adquirida (AIDS).

A autora também analisou como o discurso pela diversidade sexual é apropriado pelos/as educadores/as e articulado no campo escolar de Recife (OLIVEIRA, 2009) e do Agreste Pernambucano (OLIVEIRA, 2012). Ela percebeu que os/as profissionais resgatam as lógicas trabalhadas nos cursos de formação e os referenciais construídos em suas vivências familiares, escolares e religiosas, desencadeando processos de negociação de significados e (re) interpretação do discurso oficial. (Re)estruturam, por exemplo, as lógicas da prática da orientação sexual, dos direitos humanos e da educação inclusiva e desenvolvem posicionamentos pela caridade cristã, de cunho legalista ou de sensibilidade com os/as estudantes discriminados. $\bigcirc$ aspecto que mais se destacou no estudo foi a (re)interpretação da lógica dos direitos humanos como um discurso liberal pela tolerância, defendendo-se o acesso de pessoas 
LGBT ao ambiente escolar e o enfrentamento da homofobia desvinculado de uma reflexão sobre o papel político da escola, sobre as relações de poder ali vivenciadas, servindo, na maioria das vezes, para mascarar práticas pedagógicas heteronormativas. Tais considerações apontam para a necessidade de contextos de formação docente que busquem, além de transmitir os conceitos básicos relacionados ao tema "educação, gênero e sexualidade", desconstruir as práticas e dinâmicas já existentes e atuantes no campo escolar, favorecendo o desenvolvimento da compreensão política e da capacidade crítica dos/as educadores/as diante do cenário em questão.

Rasmussen (2006) desenvolveu um estudo com características semethantes enfocando o contexto do ensino médio em dois países: Austrália e Estados Unidos. A pesquisa teve como objetivo identificar os principais discursos sobre sexualidade e escolarização produzidos por segmentos LGBT (acadêmicos e não-acadêmicos), verificar como esses discursos se manifestam no contexto escolar e traçar alternativas para produção de teorias e práticas pedagógicas relacionadas à sexualidade. A pesquisadora entrevistou dezessete profissionais envolvidos com projetos - pesquisas, cursos de formação, elaboração de materiais escritos - sobre sexualidade e escolarização numa perspectiva LGBT. A maioria dos entrevistados/as tinha pós-graduação, sendo oito australianos/as e nove estadunidenses. Também foram analisados materiais escritos: jornais e documentos queers, feministas e pós-estruturalistas; publicações produzidas por departamentos de educação, grupos LGBT e organizações religiosas desses países.

A autora percebeu que muitos dos projetos que visam à eliminação da homofobia e do heterossexismo nas escolas descrevem, com frequência, histórias de violência e abjeção de estudantes e docentes, e que tais trabalhos acabam sendo cúmplices no processo de "objetificação" dessas pessoas. Através da análise de um caso publicado num dos principais jornais australianos sobre um garoto gay que foi agredido na escola por vários estudantes (Tsakalos's store), a autora mostra que o aluno é transformado num mero objeto de piedade, não se discute a complexidade de sua história de vida e de escolarização, tampouco os fatores que possibilitaram a escola se transformar num ambiente hostil.

Rasmussen (2006) também analisou um livro (HATTON, 1998) usado em cursos de formação de professores na Austrália e na Nova Zelândia que discute vários processos de opressão no contexto escolar. Segundo a 
pesquisadora, esse material utiliza uma série de estratégias discursivas que objetificam os/as estudantes homossexuais: ênfase no isolamento dos/as estudantes no contexto educacional, nas suas experiências de agressão física e verbal, nas tentativas de suicídio etc. Por mais que esses trabalhos tenham a intenção de encorajar práticas não homofóbicas, a autora salienta que eles não questionam as relações desiguais de poder e os investimentos efetuados para a manutenção dos processos de heteronormalização no ambiente escolar, e acabam contribuindo para a construção de estereótipos relacionados às pessoas homossexuais. Sugere que, em vez de tais estratégias, sejam desenvolvidas atividades que mostrem as diferenças entre os grupos; que debatam sobre a criação dos mecanismos de marginalização, de sustentação das diferenças e de valorização de identidades.

Outro tipo de discurso presente no material pesquisado foi o que incentiva alunos/as e professores/as a "saírem do armário". $\bigcirc$ principal exemplo é o programa conhecido como "Dia Nacional de Sair do Armário" (National Coming Out Dayl, desenvolvido em várias escolas nos Estados Unidos. Para a autora, esse discurso não leva em consideração como o processo de tornar público a orientação sexual envolve aspectos complexos relacionados ao con-

130 texto étnico, racial, religioso da pessoa e de seus familiares e, principalmente, no caso de jovens e adolescentes, ao tratamento que vai ser dispensado a eles/elas - estando implicados, nessa questão, sérios problemas de discriminação, preconceito e inclusive a manutenção ou não de suporte financeiro pela família para seus estudos e assistência à saúde. Na opinião da pesquisadora, melhor seria refletir com os/as alunos/as e professores/as sobre as diversas questões pedagógicas, políticas e morais envolvidas na construção de identidades de gênero e sexuais e, igualmente, no processo de "sair do armário". O discurso binário "ficar/sair do armário" não contribui para a discussão dos processos de produção da exclusão, não leva em consideração a natureza interativa e os processos de negociação envolvidos na construção de contextos educacionais inclusivos.

Rasmussen (2006) também analisou a produção de discursos focalizados nas experiências bem-sucedidas de docentes e discentes gays e lésbicas. Segundo a autora, tais narrativas emergem da formação de fóruns onde esses/ essas compartilham seu sucesso profissional e acadêmico. As publicações, nessa área, destacam as características exemplares desses personagens - chamados de superprofessores e superestudantes - ressaltando sua competência, 
perfil psicológico e esforço desprendido no trabalho. A ideia é fortalecer a inserção de gays e lésbicas no ambiente escolar e desconstruir imagens negativas sobre eles/as. Para a autora, esse tipo de material tem sido importante como contranarrativa em relação aos discursos conservadores e patologizantes dos grupos radicais e de algumas instituições religiosas. No entanto, ela ressalta que criar uma "iconografia sagrada" de gays e lésbicas pode ser perigoso porque não leva em consideração que também há diferenças entre essas pessoas: elas não têm o mesmo desempenho acadêmico e profissional, as mesmas história de vida, não formam um grupo homogêneo. Como em todo contexto sociocultural, as contradições também estão presentes entre aqueles e aquelas que constituem as culturas LGBT, existindo desigualdades - geracionais, raciais, étnicas, de classe. Há, inclusive, homofobia: raramente se discutem, nessas publicações, por exemplo, as experiências de professores/as e alunos/as transexuais, travestis e intersexuais.

Rasmussen (2006) destaca, ainda, alguns discursos que, pautados na própria teoria queer, defendem que a criação de categorias - lésbicas, gays, bissexuais, heterossexuais, transgêneros, intersexuais - são insuficientes para explicar as complexas configurações das identidades e rejeitam as estratégias de luta pelos direitos civis e educacionais dos grupos LGBT. Para a pesquisadora, que também se fundamenta na teoria queer e compartilha as críticas sobre o uso de categorias, os trabalhos nesse campo não podem deixar de levar em consideração que, em muitos contextos, os direitos humanos não são respeitados e, portanto, é necessário que sejam aplicadas estratégias políticas e jurídicas que garantam os direitos das pessoas LGBT.

De acordo com a autora (RASMUSSEN, 2006), o trabalho educacional pautado na teoria queer - seja de ensino, pesquisa ou planejamento - deve questionar por que o conhecimento é sexualizado e racializado; como se dá o processo de subjetivação de estudantes e docentes em contextos escolares; por que a escola valoriza algumas identidades e outras não; quais discursos sobre sexualidade e educação são permitidos, onde são e por que são; quais não são, onde não são e por que não são.

Ao discutir sobre práticas educativas comprometidas com essa perspectiva, Louro afirma:

Uma pedagogia e um currículo queer estariam voltados para o processo de produção das diferenças e trabalhariam, centralmente, 
com a instabilidade e a precariedade de todas as identidades. Ao colocarem em discussão a forma como o outro é constituído, levariam a questionar as estreitas relações do eu com o outro. A diferença deixaria de estar lá fora, do outro lado, alheia ao sujeito, e seria compreendida como indispensável para a existência do próprio sujeito: ela estaria dentro, integrando e constituindo o eu. (LOURO, 2004, p. 48).

Tais práticas precisam levar em consideração que o corpo, o prazer e o desejo são elementos que fazem parte do processo de ensino e de aprendizagem; devem questionar as estratégias heteronormativas e desconstruir os processos de estigmatização e marginalização dos sujeitos vistos como diferentes.

\section{Considerações finais}

Após caminharmos por diversas reflexões sobre gênero e discutirmos sobre as contribuições dos estudos queers para a educação em diferentes contextos e países, percebemos que, por meio de continuidades, descontinuidades, deslocamentos e rupturas, os discursos pela diversidade sexual são tecidos, saberes são instituídos, sujeitos são incluídos e/ou marginalizados.

Ao olharmos para a realidade educacional de países aonde o sistema escolar, os movimentos sociais e o campo acadêmico vêm discutindo há várias décadas a questão da diversidade sexual na escola, percebemos claramente a heterogeneidade dos discursos, a complexidade das discussões, as diferentes e contraditórias práticas pedagógicas postas em ação. Por outro lado, percebemos também que a educação brasileira encontra-se ainda em um estágio gestacional em relação a esse debate, mesmo que já possa ser percebida a mesma tendência à heterogeneidade de posições. A luta pela implantação de uma políitica educacional pela diversidade sexual e de combate à homofobia na escola, em especial, tem se mostrado extremamente árdua, complexa e atravessada por resistências no contexło brasileiro. Mesmo assim, já é possível perceber claramente a emergência de discursos oficiais e institucionais razoavelmente consolidados sobre o tema. Ao observarmos, mesmo de forma panorâmica, alguns dos movimentos que levaram ao desenvolvimento em diversas regiões dos estudos queers sobre educação e diversidade sexual, todavia, verificamos que não é suficiente simplesmente concentrar-se na formação ou 
sustentação de discursos institucionais/oficiais. É importante ainda, em nosso caso, conhecermos e analisarmos mais profundamente esses discursos, saber quem está autorizado a produzi-los, veiculá-los, em que contextos são elaborados e, sobretudo, ampliar a investigação sobre como os/as educadores/ as estão se apropriando desses discursos e articulando-os no campo escolar.

\section{Referências}

ADLER, Alfred. A ciência da natureza humana. São Paulo: Companhia Editora Nacional, 1967.

ALTMAN, Dennis Patkin. Homossexual: oppression and liberation. Sydney: Angus and Robertson, 1972.

BEAUVOIR, Simone de. O segundo sexo. Rio de Janeiro: Nova Fronteira, 1986.

BEBEL, August. Woman under socialismo. Translated by Daniel de Leon. New York: New York Labor Company, 1917.

BORRILLO, Daniel. Homofobia: história e crítica de um preconceito. Belo Horizonte: Autêntica, 2010.

BRITZMAN, Deborah. Curiosidade, sexualidade e currículo. In: LOURO, Guacira Lopes (Org.). O corpo educado: pedagogias da sexualidade. Belo Horizonte, Autêntica, 2001. O que é esta coisa chamada amor: identidade homossexual, educação e currículo.

Revista Educação e Realidade, Porto Alegre, v. 21, n. 1, p. 71-96, jan./jun. 1996.

BRYSON, Valerie. Feminist political theory: an introduction. New York: Palgrave MacMillan, 2003

BUTLER, Judit. Problemas de gênero: feminismo e subversão da identidade. Rio de Janeiro: Civilização Brasileira, 2003.

COMTE, Auguste. System of positive polity or treatise on sociology. London: Longmans Green: 1851

CONNELL, Raewyn. Gender. Cambridge: Polity Press, 2002.

COSTA, Suely Gomes. Movimentos Feministas, Feminismos. Estudos Feministas, Florianópolis, v. 12, n. 264, p. 23-36, set./dez. 2004. 
DERRIDA, Jacques. A escritura e a diferença. São Paulo: Perspectiva, 2005.

ENGELS, Friedrich. A origem da família, da propriedade privada e do Estado. Rio de Janeiro: Civilização Brasileira, 1997.

ERIKSON, Eric. Infância e sociedade. Rio de Janeiro: Zahar, 1971. Identidade, juventude e crise. Rio de Janeiro: Zahar, 1976.

EPSTEIN, Debbie; JOHNSON, Colin. Schooling sexualities. Buckingham: Open University Press, 1998.

FAUSTO-STERLING, Anne. Sexing the body: gender politics and the construction of sexuality. Nova York: Basic Books, 2000.

FIGES, Eva. Patriarchal attitudes. London: Virago, 1978.

FIRESTONE, Shulamith. The dialectic of sex. London: Women's Press, 1979.

FOUCAULT, Michel. A arqueologia do saber. Rio de Janeiro: Forense Universitária, 2007. Microfísica do poder. Rio de Janeiro: Graal, 1998.

134 GAMA, Ywanoska Maria Santos da. Gênero no currículo dos anos iniciais do ensino fundamental: concepções e vivências de professoras. 2004. 147 f. Dissertação (Mestrado em Educação) - Programa de Pós-Graduação em Educação, Universidade Federal de Pernambuco, Recife, 2004.

GLYNOS, Jason; HOWARTH, David. Logics of critical explanation in social and political theory. London: Routledge, 2007.

GREER, Germaine. The female eunuch. London: Paladin, 1979.

Sex and destiny: The Politics of Human Fertility. London: Seker \& Warburg, 1984.

GOFFMAN, Erving. A representação do eu na vida cotidiana. Petrópolis: Vozes, 1975.

Behavior in public places notes on the social organization of gatherings. New York: Free Press, 1966.

HATTON, Elizabeth $(O r g$.$) . Understanding teaching: curriculum and the social context of$ schooling. Sydney: Harcourt Brace, 1998.

HOCQUENGHEM, Guy. Homosexual desire. London: Allison \& Busby, 1978. 
HOOKS, Bell. Eros, erotismo e o processo pedagógico. In: LOURO, Guacira Lopes. O corpo educado: pedagogias da sexualidade. Belo Horizonte: Autêntica, 2001.

LOURO, Guacira Lopes. Um corpo estranho: ensaios sobre sexualidade e teoria queer. Belo Horizonte: Autêntica, 2004.

Currículo, gênero e sexualidade - o "normal, o "diferente" e o "excêntrico". In: LOURO, Guacira Lopes; FELIPE, Jane e GOELLNER, Silvania Vilodre. Corpo, gênero e sexualidade: um debate contemporâneo na educação. Petrópolis: Vozes, 2003.

2001.

(Org.). O corpo educado: pedagogias da sexualidade. Belo Horizonte: Autêntica,

Produzindo sujeitos masculinos e cristãos. In: VEIGA-NETO, Alfredo. (Org.) Crítica pós-estruturalista e educação. Porło Alegre: Sulina, 1995.

MAC AN GHAlLL, Máirtín. The making of men: masculinities, sexualities and schooling. London: Open University Press, 1994.

MAC AN GHAlLL, Mairtín; HAYWOOD, Chris. Gender, culture and society: contemporary femininities and masculinities. New York: PalgraveMacmillan, 2007.

MALINOWSKI, Bronislaw. Argonautas do pacífico ocidental: um relato do empreendimento e da aventura dos nativos nos arquipélagos da Nova Guiné Melanesia. São Paulo: Abril Cultural, 1978.

Estudios de psicologia primitiva elcomplejo de Édipo. Buenos Aires: Paidos, 1959.

Sex and repression in savage society. New York: Meridian, 1955.

MEYER, Dagmar Estermann. Gênero e Educação: teoria e política. In: LOURO, Guacira Lopes; FELIPE, Jane; GOLLNER, Silvania Vilandre. Corpo, gênero e sexualidade: um debate contemporâneo. Petrópolis: Vozes, 2003.

MEAD, Margaret. Adolescencia y cultura em Samoa. Buenos Aires: Paidos, 1978.

Sexo e temperamento. São Paulo: Perspectiva, 1969.

MILL, John Stuart. The subjection of women. New York: Dover Thrift Editions, 1869.

MILLET, Kate. Sexual politics. London: Virago, 1985.

MIRANDA, Marcelo Henrique; OLIVEIRA, Aurenéa Maria. A visibilidade de corpos gendrados e seus desdobramentos políticos e cotidianos. Recife: Universidade Federal de 
Pernambuco, 2012. (Relatório parcial do Projeto de Pesquisa financiado pelo CNPq - Edital MCT/CNPq/SPM-PR/MDA 020/20101.

MISKOLCl, Richard. A Teoria Queer e a questão da diferença. In: Cadernos de atividades e resumos do $16^{\circ}$ Congresso de Leitura do Brasil $\left(16^{\circ}\right.$ COLE), v. 1. p. 1-19. Campinas: Associação de Leitura do Brasil, 2007.

MISKOLCl, Richard; PELÚCIO, Larissa. Fora do Sujeito e Fora do Lugar: reflexões sobre performatividade a partir de uma etnografia entre travestis. Gênero, Niteroi, v. 7, n. 2, p. 257-267, jan./jun. 2007.

MORGAN, Robin. Sisterhood is global: The international women's movement anthology. Harmondsworth: Penguin, 1984.

NOVENA, Nádia Patrízia. A sexualidade na organização escolar: narrativas do silêncio. 2004. 255 f. Tese (Doutorado em Sociologia). Programa de Pós-graduação em Sociologia, Universidade Federal de Pernambuco, Recife, 2004.

OlIVEIRA, Anna Luiza Martins de. $\mathbf{O}$ discurso pela diversidade sexual entre profissionais da educação do agreste pernambucano: delineamento das lógicas políticas e sociais emergentes no campo escolar. Recife: Universidade Federal de Pernambuco, 2012. (Relatório Parcial do Projeto de Pesquisa aprovado no edital FACEPE/CNPq 10/20101.

Tolerância, piedade, imposição? $\bigcirc$ discurso pela diversidade sexual (re) articulado por professores/as e gestores/as no cotidiano escolar. In: SEMINÁRIO BRASILEIRO, 4., SEMINÁRIO INTERNACIONAL DE ESTUDOS CULTURAIS E EDUCAÇÃO, 1., 2011 , Canoas. Anais... Canoas: Universidade Luterana do Brasil (ULBRA)/Universidade Federal do Rio Grande do Sul, 2011.

O discurso pedagógico pela diversidade sexual e sua (re) articulação no campo escolar. 2009. 271 f. Tese (Doutorado em Educação) - Programa de Pós-Graduação em Educação, Universidade Federal de Pernambuco, Recife, 2009.

OlIVEIRA, Anna Luiza Martins de; OlIVEIRA, Gustavo Gilson Sousa de; NOVENA, Nadia Patrízia. Os discursos sobre diversidade sexual na educação: deslocamentos e novas articulações. In: ENCONTRO NACIONAL DE DIDÁTICA E PRÁTICA DE ENSINO - ENDIPE, 15., 2010, Belo Horizonte. Anais... Belo Horizonte: Universidade Federal de Minas Gerais, 2010.

OLIVEIRA, Maria. Sexualidade na escola: representações dos docentes do ensino fundamental. 2001.163 f. Dissertação. (Mestrado em Educação) - Programa de Pós-Graduação em Educação, Universidade Federal de Pernambuco, Recife, 2001. 
PARSONS, Talcott. Family structure and the socialization of the child. In: PARSONS, Talcott; BALES, Robert Freed (Org.). Family, socialization and interaction process, London: Routledge, 1956.

RASMUSSEN, Mary Louise. Becoming subjects: sexualities and secundary schooling. Londres: Routledge, 2006.

RASMUSSEN, Mary Louise; ROFES, Eric; TALBURT, Susan. Sexualities: plesuare, subversion and insubordination in and out of schools. Nova York: Palgrave Macmillan, 2004.

SEIDMAN, Steven. "Deconstructing queer theory or the under-theorization of the social and the ethical". In: NICHOLSON, Linda; SEIDMAN, Steven (Org.) Social postmodernism. Beyond identity politics. Cambrige: Cambridge University Press, 1995.

TAVARES, Liliana Barros. Deixem que digam, que pensem, que falem: a homofobia na visão dos formandos de licenciatura da UFRPE. 2006. 89 f. Dissertação (Mestrado em Educação) - Programa de Pós-Graduação em Educação, Universidade Federal de Pernambuco, Recife, 2006.

VAERTING, Mathilde. The dominant sex: a study in the sociology of sex differentiation. Westport: Hyperion, 1921.

WARD, Lester. Dynamic sociology - or applied social science as based upon statical sociology and the less complex sciences. New York: D. Appleton \& Company, 1883.

WEEKS, Jeffrey. Coming out: homosexual politics in britain from the nineteenth century to the present. Londres: Quartet Books, 1990.

Profa. Dra. Anna Luiza Araújo Ramos Martins de Oliveira Universidade Federal de Pernambuco

Núcleo de Formação Docente Centro Acadêmico do Agreste Grupo de Pesquisa (CNPq)| Subjetividades Coletivas, Processos de Resistência e Inovações Políticas em Práticas Educacionais E-mail | alarmo@uol.com.br 
Profa. Dra. Aurenéa Maria de Oliveira Universidade Federal de Pernambuco Centro de Educação

Departamento de Fundamentos Sócio-Filosóficos da Educação Grupo de Pesquisa (CNPq)| Subjetividades Coletivas, Processos de Resistência e Inovações Políticas em Práticas Educacionais E-mail | arenea@yahoo.com.br

Prof. Dr. Marcelo Henrique Gonçalves de Miranda Universidade Federal de Pernambuco Centro de Educação

Departamento de Fundamentos Sócio-Filosóficos da Educação Grupo de Pesquisa (CNPq)| Subjetividades Coletivas, Processos de Resistência e Inovações Políticas em Práticas Educacionais E-mail |mm.marcelohenrique@yahoo.com.br

Recebido 16 ago. 2012 Aceito 17 dez. 2012 